\title{
Development of Site Specific Optimal Tilt Angle Model for Fixed Tilted Plane PV Installation in Akwa Ibom State, Nigeria
}

\author{
Anyanime Tim Umoette, Mbetobong Udo Festus, Emmanuel A. Ubom \\ Department of Electrical \& Electronic Engineering, Akwa Ibom State University, Mkpat Enin, Nigeria
}

Email address:

simeonoz@yahoo.com (A. T. Umoette)

\section{To cite this article:}

Anyanime Tim Umoette, Mbetobong Udo Festus, Emmanuel A. Ubom. Development of Site Specific Optimal Tilt Angle Model for Fixed Tilted Plane PV Installation in Akwa Ibom State, Nigeria. Science Journal of Energy Engineering. Vol. 4, No. 6, 2016, pp. 50-55. doi: $10.11648 /$ j.sjee.20160406.11

Received: October 25, 2016; Accepted: November 18, 2016; Published: January 12, 2017

\begin{abstract}
Photovoltaic (PV) panels' orientation (azimuth angle) and tilt angle significantly affect the energy output of PV power plants. The reason is because the photovoltaic panels produce more electric energy when their surfaces are perpendicular to the sun's rays. Researchers have developed models for estimating the optimal tilt angle for any given location across the globe. In this paper, a site specific model is developed for more accurate estimation of the optimal tilt angle for fixed-tilt angle PV installations at the Ibom E-Library in Uyo metropolis, Akwa state of Nigeria. The solar radiation data used for the study was obtained from the National Aeronautics and Space Administration Surface meteorology and Solar Energy (NASA SSE) website. PVsyst simulation software was used to perform the transposition of the global radiation on horizontal plane to tilted plane. For the location with latitude of $5.123^{\circ}$ the existing model estimated the optimal tilt angle as $7.16035^{\circ}$ whereas, the site-specific model estimated $11.5^{\circ}$ for the optimal tilt angle. The model has prediction accuracy of $99.77 \%$ and root mean square error of 0.002567 . The optimal tilt angle model can be employed for fixed tilted plane PV installations in the nearby locations.
\end{abstract}

Keywords: Photovoltaic, Irradiation, Tilt Angle, Azimuth Angle, Transposition, Transposition Factor, Optimal Tilt Angle, Fixed Tilted Plane

\section{Introduction}

Photovoltaic (PV) orientation (azimuth angle) and tilt angle significantly affect the energy output of PV power plants. Generally, the optimal azimuth angle for PV installations, is $0^{\circ}$. However, optimal tilt angle is dependent on parameters such as, one, the latitude of the geographical location where the PV panels are to be installed and two, the time of year considered in the PV energy production system. With respect to the second issue, the optimal tilt angle varies all through the year and detailed mathematical equations exist to determine the optimal tilt angle at any given day. However, in practice, for fixed tilted plane PV installations, optimal tilt angle are determined approximately based on yearly or seasonal solar radiation. In another case, the tilt angle is based on the worst case month of solar radiation. The popular model for computing optimal tilt angle based on yearly average solar radiation is $3.7+0.69|\phi|$; where $\phi$ is the latitude of the location where the PV panel is to be installed.

Despite the wide adoption of the given model, it fails to give the optimal tilt angle for fixed tilted plane PV installation in Uyo, Akwa Ibom state of Nigeria. Consequently, in this paper, solar radiation data from the National Aeronautics and Space Administration Surface meteorology and Solar Energy (NASA SSE) website and PVSyst simulation software are used to study the variations in the transposition factor for fixed tiled plane PV installation in Ibom E-Library in Uyo. Mathematical model for computing the optimal tilt angle is developed from the simulation results. The transposed solar radiation on tilted plane and the transposition factor for the new model is compared with those of the existing model. 


\section{Review of Relevant Literature}

After passing through the Earth's atmosphere, solar radiation includes both a direct component from the Sun itself and a diffuse component which is made up of radiations reflected off clouds, as well as moisture vapour and other particulates within the sky $[1,2]$. The satellite-derived NASA SSE solar radiation data consist of the global horizontal irradiance and the direct component also on the horizontal plane $[3,4,5,6]$. The global horizontal radiation is the sum of both the diffuse radiation and the direct radiation components as measured incident on horizontal plane [8].

In practice, the irradiation on the tilted plane of the PV array is used in the computation of the solar energy potential at any location [9]. However, in many cases PV panels are installed on tilted planes, as such, the irradiance on the tilted plane has to be estimated. Transposition is the calculation of the incident irradiance on a tilted plane, from the horizontal irradiance data $[9,10,11]$. PVsyst offers two transposition models, namely, Hay's model and Perez model. In this study, the Perez transposition model as implemented in PSyst is adopted.

The radiation that reflects from surroundings (so called albedo) is of importance for some surfaces that are inclined under some angle to the horizontal surface. This radiation is mainly diffuse and comes to the receiving surface under different angles $[12,13]$. The intensity of the reflected solar radiation depends on the surroundings that it is reflected from. The total solar radiation on tilted surface (HT) is the sum of direct or beam solar radiation (HB), sky diffuse solar radiation (HS) and the ground reflected radiation (HR) and is given by $[14,1,15]$ :

$$
\mathrm{HT}=\mathrm{HB}+\mathrm{HS}+\mathrm{HR}
$$

When global irradiation on horizontal plane is given, then the irradiation on the inclined plane is given as $[16,17]$ :

$\frac{\mathrm{G}(\beta)}{\mathrm{G}\left(\beta_{\mathrm{opt}}\right)}=1+4.46 *\left(10^{-4}\right)\left(\beta-\beta_{\mathrm{opt}}\right)-1.19 *\left(10^{-4}\right)\left(\beta-\beta_{\mathrm{opt}}\right)^{2}$

where $\mathrm{G}$ in $\mathrm{Wh} / \mathrm{m} 2$ or $\mathrm{KWh} / \mathrm{m}^{2}$ is the global irradiation and the optimal inclination can be calculated with:

$$
\beta_{\text {opt }}=3.7+0.69|\varnothing|
$$

where $\varnothing$ is the local latitude, $\beta$ is the tilt angle, and $\beta_{\text {opt }}$ is the tilt angle, where $\beta, \beta_{\text {opt }}$ and $\varnothing$ are in degrees.

\section{Methodology}

Step 1. Get The Site Location Data

The geographic coordinates of the PV installation site are obtained from Google map. The site location data are; IBB Avenue, Uyo, Nigeria at the coordinates; latitude5.015197, 7.913180 .

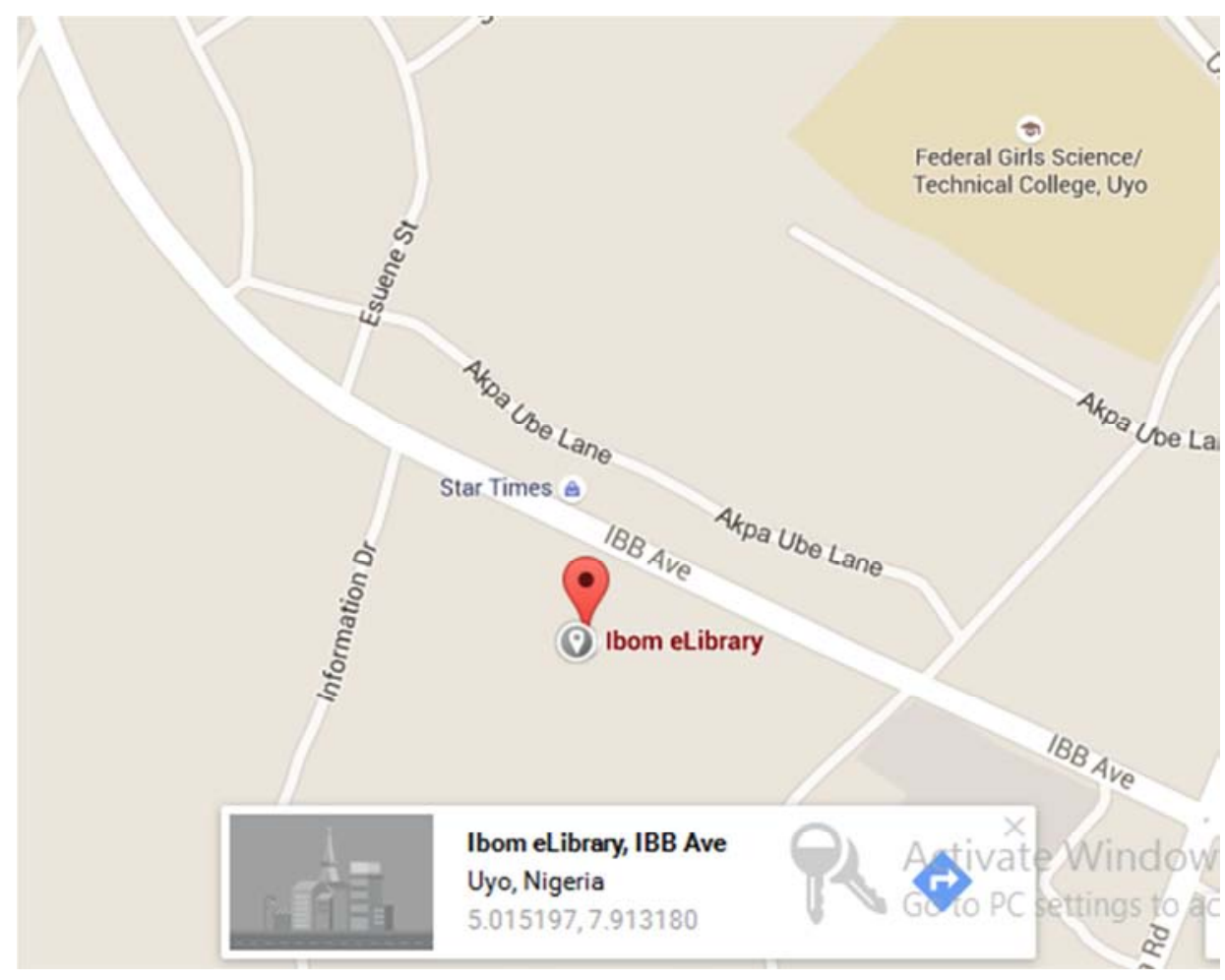

Figure 1. The Google Map Location Data for the PV Installation Site at Ibom E-Library, Uyo, Nigeria.

Step 2. Download The Solar Irradiation Data

PVSyt Tool Dialogue Box (Figure 2) is used to download 22-year monthly average global radiation on horizontal plane from NASA SSE website for the given PV Installation site at Ibom E-Library, Uyo, Nigeria. 


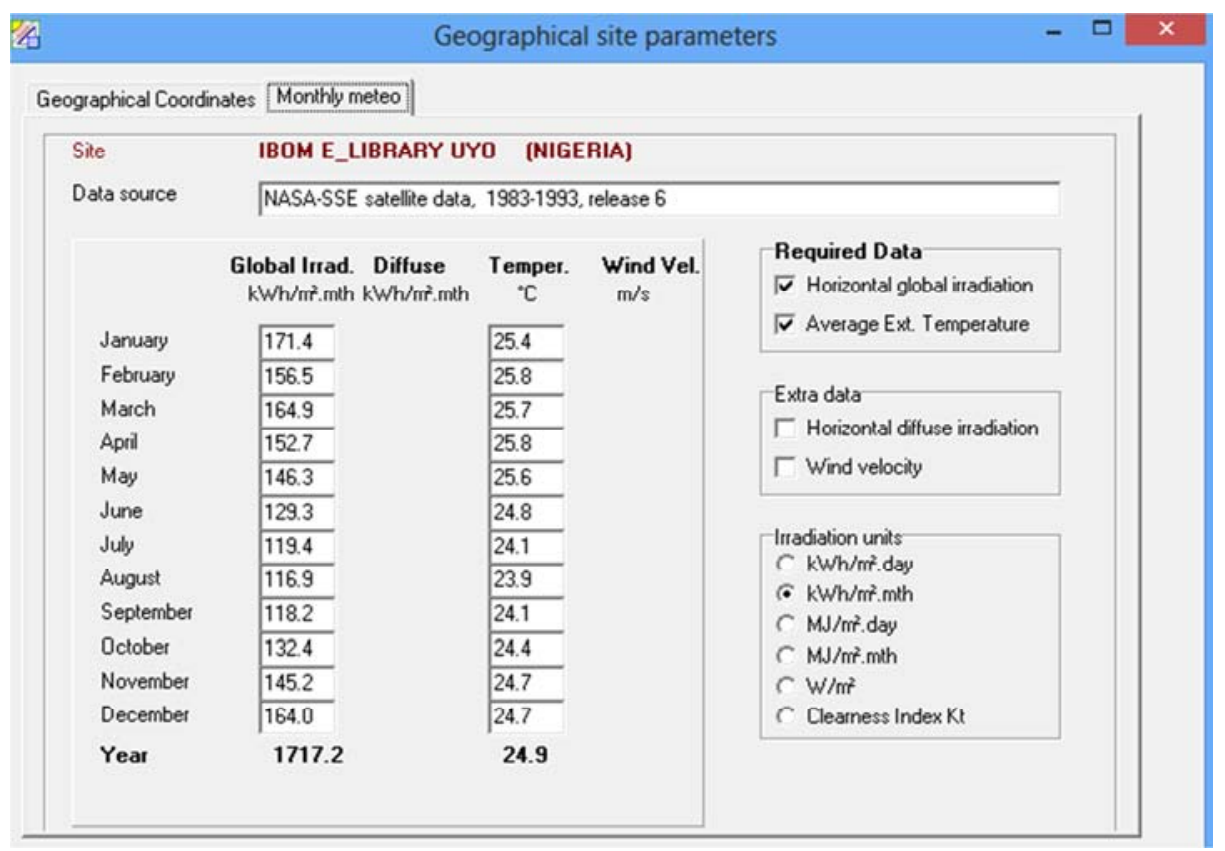

Figure 2. PVSyt Tool Dialogue Box for downloading the monthly average global radiation on horizontal plane from NASA SSE website.

Step 3. Decomposition Of The Global Irradiation On Horizontal Plane To Its Component Parts

PVsyst simulation software is used to first decompose the Global irradiation on horizontal plane into its component parts, namely; horizontal diffused irradiation and horizontal beam irradiation, as well as the albedo component.

Step 4. Transposition Of The Global Irradiation On Horizontal Plane To The Global Irradiation On Tilted Plane

The PVSyst is used to transpose the Global irradiation on horizontal plane into its Global irradiation on tilted plane for any selected Tilt angle.

Step 5. Compute The Transposition Factor

The transposition factor (TF) is the ratio of the Global Irradiation on tilted plane to the Global Irradiation on horizontal plane

Transposition Factor $(T F)=\frac{\text { Global irradiation on tilted plane }}{\text { Global irradiation on horizontal plane }}$

In step 4, PVSyst provides monthly and yearly average of the Global irradiation on horizontal plane along with the Global irradiation on tilted plane for the selected tilt angle. As such, in step 5, the transposition factor is computed for each month and for the yearly average data.

Step 6. Generate The Data Set and Model For The Computation Of The Optimal Tilt Angle

In order to generate the model for computing the optimal tilt angle, step 4 and step 5 are repeated for a set of different tilt angles starting from zero to a value that is at least twice the latitude of the location. The transposition factor of the yearly average irradiation is plotted against the tilt angle and a trend line equation is fitted on the graph plots to generate the model for computing the optimal tilt angle. Specifically, the optimal tilt angle is obtained by finding the tilt angle at which the gradient of the trend line equation is zero. The optimal tilt angle obtained from the model is then compared with the tilt angle obtained from the popularly used equation 3.3 .

Performance Analysis Of The Model

In this paper, in order to validate the effectiveness of the proposed model, Root Mean Square Error (RMSE) and Prediction Accuracy (PA) were calculated. The Root Mean Square Error (RMSE) is calculated as follows:

$$
\operatorname{MSE}=\sqrt[2]{\left\{\frac{1}{n}\left[\sum_{i=1}^{i=n}\left|H T_{(\text {actual })(i)}-H T_{(\text {predicted })(i)}\right|^{2}\right]\right\}}
$$

where:

$H T_{(\text {actual })(i)}$ is the actual solar radiation on tilted surface in $\mathrm{KWh} / \mathrm{m}^{2}$

$H T_{(\text {predicted)(i) }}$ is the predicted solar radiation on tilted surface in $\mathrm{KWh} / \mathrm{m}^{2}$

$\mathrm{n}$ is the number of data points.

Then, the accuracy (PA in \%) based on mean absolute percentage deviation (MAPD) or Mean Absolute Percentage Error (MAPE) is calculated as follows:

$$
\mathrm{PA}=\left\{1-\frac{1}{n}\left(\sum_{i=1}^{i=n}\left|\frac{\left|H T_{(\text {actual })(i)}-H T_{(\text {predicted })(i)}\right|}{H T_{(\text {actual })(i)}}\right|\right)\right\} * 100 \%
$$

\section{Results and Discussion}

Table 1 shows sample data on the global irradiation on horizontal plane decomposed and transposed onto a $6^{\circ}$ tilted plane with albedo component of 0.20 or $20 \%$. Figure 3 shows the monthly and yearly transposition factor at tilt angle of 6 degrees and azimuth angle of 0 . According to Figure 3, December has the highest transposition factor whereas June has the lowest transposition factor. The tilt angle in this case is determined in PVSyst to suit the yearly average solar irradiation data. Accordingly, the result in Figure 3 shows that about 6 months (half of the year) have transposition factor above 1 whereas another 6 months (half of the year) have their 
transposition factors less than 1 . The result would have been different if the tilt angle is determined based on a given seasonal or monthly average irradiation data. However, the focus of this paper is on the optimal tilt angle based on the yearly average irradiation data.

Table 1. Sample Data on the Global Irradiation on Horizontal Plane Decomposed and Transposed Onto a $6^{\circ}$ Tilted Plane With Albedo Component Of 0.20 or $20 \%$.

\begin{tabular}{|c|c|c|c|c|c|}
\hline \multicolumn{6}{|c|}{ Plane: Tilt $6^{\circ}$; Azimuth $0^{\circ}$; Albedo 0.20} \\
\hline & $\begin{array}{l}\text { Global Irradiation on } \\
\text { Horizontal Plane }\end{array}$ & $\begin{array}{l}\text { Diffused Irradiation on } \\
\text { Horizontal Plane }\end{array}$ & $\begin{array}{l}\text { Beam Irradiation on } \\
\text { Horizontal Plane }\end{array}$ & $\begin{array}{l}\text { Global Irradiation } \\
\text { on Tilted Plane }\end{array}$ & Transposition Factor \\
\hline & $\mathrm{KWh} / \mathrm{m}^{2} \cdot \mathrm{mth}$ & $\mathrm{KWh} / \mathrm{m}^{2} \cdot \mathrm{mth}$ & $\mathrm{KWh} / \mathrm{m}^{2} \cdot \mathrm{mth}$ & $\mathrm{KWh} / \mathrm{m}^{2} \cdot \mathrm{mth}$ & \\
\hline Jan & 171.4 & 62.3 & 109.1 & 180.3 & 1.0519 \\
\hline Feb & 156.5 & 61.15 & 95.4 & 161.3 & 1.0307 \\
\hline Mar & 164.9 & 72.09 & 92.8 & 166.4 & 1.0091 \\
\hline Apr & 152.7 & 74.7 & 78 & 150.6 & 0.9862 \\
\hline May & 146.3 & 75.71 & 70.6 & 142.2 & 0.9720 \\
\hline Jun & 129.3 & 73.5 & 55.8 & 125.1 & 0.9675 \\
\hline Jul & 119.3 & 68.94 & 50.4 & 116.1 & 0.9732 \\
\hline Aug & 116.9 & 80.07 & 36.8 & 115.2 & 0.9855 \\
\hline Sep & 118.2 & 75.19 & 43 & 118.1 & 0.9992 \\
\hline Oct & 132.4 & 80.37 & 52 & 134.6 & 1.0166 \\
\hline Nov & 145.2 & 72.04 & 73.2 & 150.9 & 1.0393 \\
\hline Dec & 164 & 66.33 & 97.7 & 173.2 & 1.0561 \\
\hline Year & 1717.1 & 862.38 & 854.8 & 1733.9 & 1.0098 \\
\hline
\end{tabular}

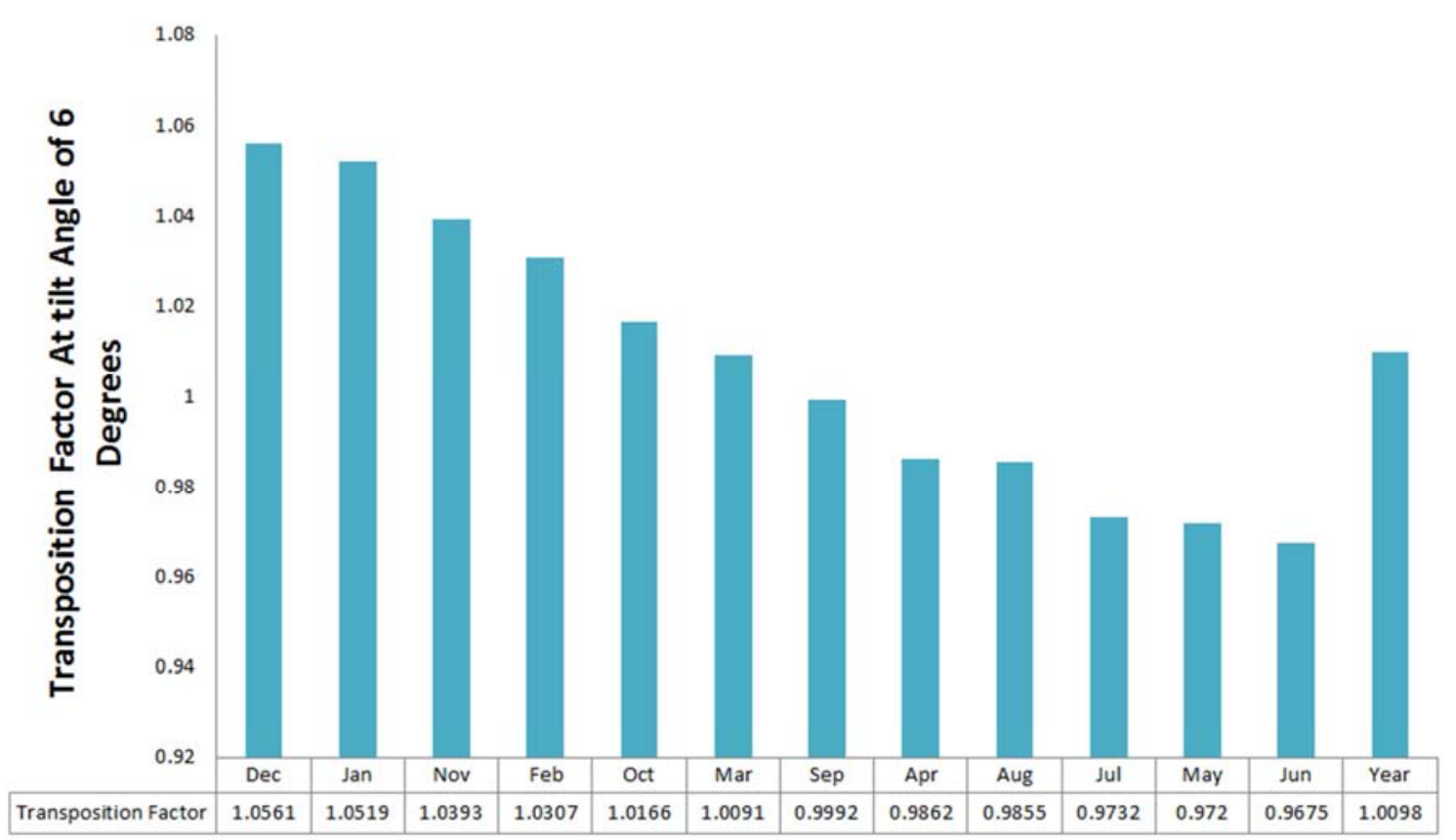

Figure 3. The Monthly and Yearly Transposition Factor At tilt Angle of 6 Degrees.

Table 2. The Monthly and Yearly Transposition factor For Different Tilt Angles.

\begin{tabular}{|c|c|c|c|c|c|c|c|c|}
\hline Tilt Angle in degrees & $0^{\circ}$ & $3^{\circ}$ & $6^{\circ}$ & $9^{\circ}$ & $12^{\circ}$ & $15^{\circ}$ & $18^{\circ}$ & $21^{\circ}$ \\
\hline Jan & 1 & 1.027 & 1.052 & 1.074 & 1.094 & 1.111 & 1.126 & 1.138 \\
\hline Feb & 1 & 1.017 & 1.031 & 1.042 & 1.052 & 1.059 & 1.065 & 1.067 \\
\hline Mar & 1 & 1.005 & 1.009 & 1.01 & 1.01 & 1.007 & 1.001 & 0.994 \\
\hline Apr & 1 & 0.994 & 0.986 & 0.976 & 0.964 & 0.95 & 0.934 & 0.917 \\
\hline May & 1 & 0.987 & 0.972 & 0.955 & 0.936 & 0.915 & 0.893 & 0.869 \\
\hline Jun & 1 & 0.985 & 0.968 & 0.948 & 0.928 & 0.906 & 0.882 & 0.856 \\
\hline Jul & 1 & 0.987 & 0.973 & 0.957 & 0.939 & 0.92 & 0.898 & 0.875 \\
\hline Aug & 1 & 0.994 & 0.985 & 0.976 & 0.965 & 0.952 & 0.937 & 0.92 \\
\hline Sep & 1 & 1.001 & 0.999 & 0.996 & 0.991 & 0.984 & 0.975 & 0.964 \\
\hline Oct & 1 & 1.009 & 1.017 & 1.022 & 1.026 & 1.027 & 1.026 & 1.023 \\
\hline Nov & 1 & 1.021 & 1.039 & 1.056 & 1.07 & 1.082 & 1.092 & 1.099 \\
\hline Dec & 1 & 1.029 & 1.056 & 1.08 & 1.102 & 1.123 & 1.14 & 1.154 \\
\hline Annual Average & 1 & 1.006 & 1.01 & 1.012 & 1.011 & 1.009 & 1.005 & 0.998 \\
\hline
\end{tabular}


Figure 4 shows the plot of the yearly transposition factor for different tilt angles. The quadratic trend line model fitted to the transposition factor plots is given as:

$$
\mathrm{Y}=-0.0001 \mathrm{x}^{2}+0.0023 \mathrm{x}+1.0026
$$

where $\mathrm{Y}$ is the transposition factor and $\mathrm{x}$ is the tilt angle I degrees.
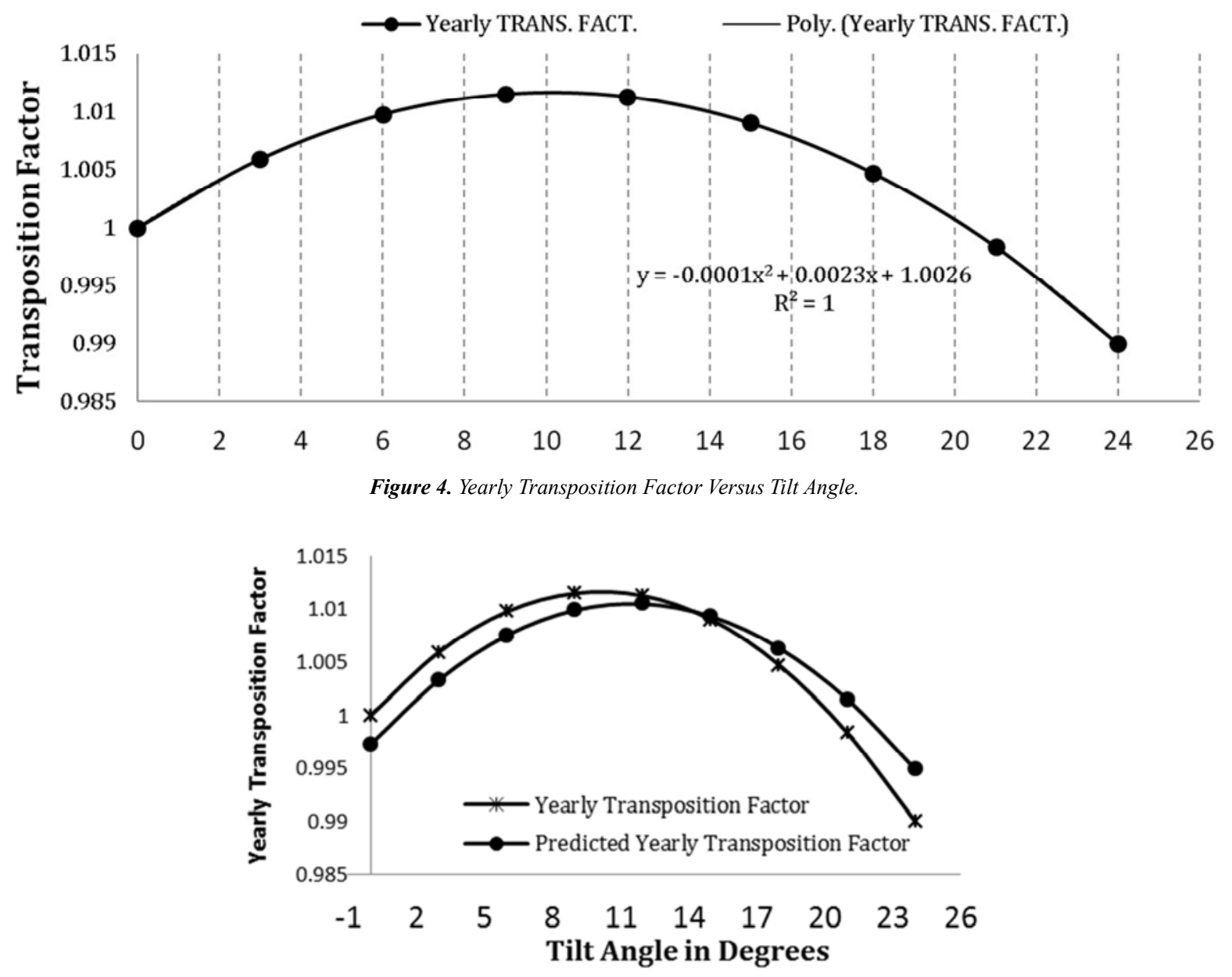

Figure 5. Actual and Predicted Yearly Transposition Factor vs Tilt Angle.

Figure 5 shows the actual and predicted yearly transposition factor versus tilt angle. The prediction accuracy of the model in Equation 4.1 is $99.77 \%$ with root mean square error of 0.002567 . The slope of the quadratic trend line polynomial model of Equation 4.1 is given as:

$$
\mathrm{Y}^{\prime}=-0.0002 \mathrm{X}+0.0023
$$

The optimal tilt angle, $x_{\text {opt }}$ is the tilt angle at which the slope in Equation 4.2 is zero. Hence,

$$
x_{\text {opt }}=\frac{0.0023}{0.0002}=11.5
$$

The optimal tilt angle from Equation 3.3 is computed as $\beta_{\text {opt }}=3.7+0.69|\varnothing|=3.7+0.69|5.015|=7.16 \approx 7$ degees . From Figure 5 at $\beta_{o p t}=x_{o p t}=7$, the transposition factor is 1.00852 where at $\beta_{\text {opt }}=x_{\text {opt }}=11.5 \approx 12$ the transposition factor is 1.01052. Essentially, the predicted optimal tilt angle based on the existing model is less than the optimal tilt angle as given in Figure 5 The new model developed in this paper gives a better prediction result for the optimal tilt angle.

\section{Conclusion and Recommendation For Further Works}

\subsection{Conclusion}

In this paper, a site specific model is developed for computing the optimal tilt angle based on the yearly average solar irradiation. The model is developed for PV power installation at a given site, namely, Ibom E-library in Uyo Akwa Ibom state of Nigeria. The model is developed through the use of PVSyst simulation software and satellite-derived NASA SSE solar radiation data on the global irradiation the horizontal plane. The result showed that the new model developed in this paper predicted the optimal tilt angle better than the existing model that is widely used by PV designers. The study shows how to obtain such optimal tilt angle model for any given location across the globe. 


\subsection{Recommendation for Further Works}

The study in this paper has focused on the optimal tilt angle with respect to the yearly average. Further work is required to determine the seasonal or monthly optimal tilt angles. Also, further work is required to extend the work to determine the effect of selecting non-optimal tilt angle on the performance of the PV plants.

\section{References}

[1] Aggarwal RK. "Estimation of Total Solar Radiation on Tilted Surface". Journal of Environmental Engineering And Technology Vol. 2, No. 1, January 2013.

[2] Thornton PE, Hasenauer H, White MA. "Simultaneous estimation of daily solar radiation and humidity from observed temperature and precipitation: an application over complex terrain in Austria." Agricultural and forestmeteorology 104.4, P255-271, 2000.

[3] Ramachandra TV, Jain R, Krishnadas G. "Hotspots of solar potential in India". Renewable and Sustainable Energy Reviews, 15 (6), 3178-3186, 2011.

[4] Mondal MA. H, Islam AS. "Potential and viability of grid-connected solar PV system in Bangladesh". Renewable energy, 36 (6), 1869-1874, 2011.

[5] Breyer C, Schmid J. "Global Distribution of optimal Tilt Angles for fixed tilted PV Systems." Horizon 4444444.2, 2010.

[6] Khan MJ, Iqbal MT. "Wind energy resource map of Newfoundland". Renewable energy, 29 (8), 1211-1221, 2004.

[7] Rigollier C, Bauer O, Wald L. "On the clear sky model of the ESRA-European Solar Radiation Atlas - with respect to the Heliosat method". Solar energy, 68 (1), 33-48, 2000.
[8] Huld T, Šúri M, Dunlop ED. "Comparison of potential solar electricity output from fixed-inclined and two-axis tracking photovoltaic modules in Europe". Progress in photovoltaics: Research and Applications, 16 (1), 47-59, 2008.

[9] Gueymard CA. "Direct and indirect uncertainties in the prediction of tilted irradiance for solar engineering applications”. Solar Energy, 83 (3), 432-444, 2009.

[10] Elminir HK, Ghitas AE, El-Hussainy F, Hamid R, Beheary MM, Abdel-Moneim KM. "Optimum solar flat-plate collector slope: case study for Helwan, Egypt". Energy Conversion and Management, 47 (5), 624-637, 2006.

[11] Zhi C, Bingfeng Y, Pingjun S. "A calculating method of albedo and experimental study of its influence on building heat environment in summer". Journal of solar energy engineering, 129 (2), 243-248. 2007.

[12] Radosavljević J, Đorđević A. "Defining of the intensity of solar radiation on horizontal and oblique surfaces on earth". Factauniversitatis, Series: working and living environmental protection, 2 (1), 2001.

[13] Shukla KN, Rangnekar S, Sudhakar K. "Comparative study of isotropic and anisotropic sky models to estimate solar radiation incident on tilted surface: A case study for Bhopal, India”. Energy Reports, 1, 96-103, 2015.

[14] Ahmad MJ, Tiwari GN. "Optimization of tilt angle for solar collector to receive maximum radiation". The Open Renewable Energy Journal, 2 (1), 19-24, 2009.

[15] Perpinan O, Lorenzo E, Castro MA. On the calculation of energy produced by a PV grid-connected system. Progress in Photovoltaics: research and applications, 15 (3), 265-274, 2007.

[16] Lorenzo E. "Energy Collected and Delivered by PV Modules." Handbook of Photovoltaic Science and Engineering, Second Edition: 984-1042. 